\title{
Effects of atorvastatin on porcine aqueous humour outflow and trabecular meshwork cells
}

\author{
LIN CONG, SHUHAO FU, JINLING ZHANG, JIN ZHAO and YUYAN ZHANG \\ Department of Ophthalmology, Huashan Hospital, Fudan University, Shanghai 200040, P.R. China
}

Received January 25, 2017; Accepted July 27, 2017

DOI: $10.3892 / \mathrm{etm} .2017 .5353$

\begin{abstract}
Primary open-angle glaucoma (POAG) with complex pathogenesis is one of the many major causes of blindness. It is widely accepted that the major cause of POAG is the dysregulation of the trabecular meshwork (TM), which regulates the resistance to aqueous humour outflow. Intraocular pressure is elevated with increasing outflow resistance in the conventional pathway, which consists of the TM and Schlemm's canal. The TM is a filter made up of extracellular matrix (e.g., collagens), most of which is organized into a network of beams covered by endothelial-like trabecular cells. Currently, lack of effective anti-glaucoma drugs acting on TM to normalize trabecular outflow represents a bottleneck for POAG therapy. Atorvastatin, a lipid-lowering drug, has been proven to be of benefit for POAG. The present study aimed to investigate the possible mechanisms of action of atorvastatin on the TM by using a porcine aqueous humour outflow model in vivo and TM cells in vitro. Perfusion of enucleated porcine eyes with atorvastatin $(50-200 \mu \mathrm{M})$ for $2 \mathrm{~h}$ increased aqueous humour outflow $(\mathrm{P}<0.05, \mathrm{n}=6)$, possibly via regulating the morphology of TM cells and the distribution of the cytoskeleton. Atorvastatin decreased adhesion molecules at the mRNA and protein level. No cytotoxicity of atorvastatin on TM cells was observed at concentrations of $<100 \mu \mathrm{M}$. The atorvastatin-induced effects mentioned above were reversible after removal of the compound only if the atorvastatin concentration was $<100 \mu \mathrm{M}$. The present study demonstrated that atorvastatin efficaciously elevated aqueous humour outflow, possibly due to affecting TM-cell morphology, cytoskeleton and cell junctions. Statins may be potential therapeutic agents for lowering intraocular pressure in POAG.
\end{abstract}

Correspondence to: Dr Yuyan Zhang, Department of Ophthalmology, Huashan Hospital, Fudan University, 12 Middle Urumqi Road, Shanghai 200040, P.R. China

E-mail: yuyan8688@163.com

Key words: atorvastatin, trabecular meshwork, aqueous humour outflow, open-angle glaucoma

\section{Introduction}

Elevated intraocular pressure (IOP) is a major cause for glaucoma. Aqueous humour outflow mostly occurs via the conventional outflow pathway, i.e. the trabecular meshwork (TM) and Schlemm's canal. Increased resistance in the TM to aqueous humour outflow leads to elevation of IOP in patients with primary open-angle glaucoma (POAG) $(1,2)$. It is considered that increases in the resistance of aqueous humour outflow through the conventional pathway in TM may be caused by overexpression of matricellular proteins and substantial enhancement of the fibrillar extracellular matrix (ECM) and cell-cell interactions (3-12). However, at present, no effective treatment for POAG targeting this conventional pathway is available (13).

In addition, TM cells possess smooth muscle cell-like properties. TM cell contraction and relaxation affects the intercellular space, the state of cell-cell junctions and cell-ECM interactions, and consequently modulates aqueous outflow through the TM tissue. The actomyosin system, composed of actin microfilaments and associated proteins, is presented in essentially all cells, as well as highly organized in TM cells (10). The actomyosin system has a critical role in regulating cellular morphology, volume, contractility, adhesion to adjacent cells and ECM production. Such modifications modulate the hydrodynamics of the aqueous humour outflow pathway at the cellular level, which is supported by the findings that actin-disrupting agents or inhibitors of specific protein kinases regulate these parameters directly or indirectly (14-16).

It is well known that statins prevent the progression of coronary artery disease, stroke and neuronal cell death after ischemic injury (17-21). Statins indirectly inhibit the synthesis of Rho guanine triphosphatase (GTPase) to affect the organization of the actin cytoskeleton (22), affect aqueous outflow associated with a reduction in membrane-bound Rho GTPase levels, a decrease in myosin light-chain (MLC) phosphorylation and changes in TM cell shape (23). Rho GTPase has an important role in actin cytoskeletal organization and cell adhesion via modulation of MLC phosphorylation. (24-27) Activation of the Rho/Rho-associated protein kinase (ROCK) pathway results in TM contraction. By contrast, inhibition of the Rho/ROCK pathway causes relaxation of TM with a subsequent increase in outflow facility and reduction in IOP (28). 
Statins also reduce the risk of POAG in hyperlipidemia patients (29), of note, they were reported to lower the frequency of glaucoma progression via a mechanism that has remained elusive (30). Thus, it is of great importance to understand the underlying mechanism of the protective action of statins on glaucoma. It is thought that the effect of statins to improve glaucoma progression may be secondary to their effects on blood lipids to reduce IOP (31). Atorvastatin is the most frequently used statin for lipid control and may also have applications in other conditions (32-34). However, the role of atorvastatin in modifying IOP and aqueous humour outflow has remained to be fully elucidated. The aim of the present study was to determine the effect of atorvastatin on pathways regulating aqueous outflow and TM cells.

\section{Materials and methods}

Reagents and apparatus. Atorvastatin, purchased from Sigma-Aldrich (Merck KGaA, Darmstadt, Germany), was dissolved in DMSO (Sigma-Aldrich; Merck KGaA) at $0.05 \mathrm{~mol} / 1$ as a stock. The perfusion pump system was purchased from Harvard Bioscience (Holliston, MA, USA). Fluorescein isothiocyanate (FITC)-phalloidin (catalogue number: 40735ES75) was purchased from Yeasen (Shanghai, China). Anti-vinculin antibody (catalogue number: BM4051) and anti- $\beta$-catenin antibody (catalogue number: BM3905) were purchased from Boster Biological Technology (Wuhan, China). High-glucose Dulbecco's modified Eagle's medium (DMEM) and fetal bovine serum (FBS) were obtained from Gibco (Thermo Fisher Scientific, Inc., Waltham, MA, USA). A Cell Counting Kit-8 (CCK-8) was obtained from Dojindo Molecular Technologies, Inc. (Kumomoto, Japan). Oligonucleotide primers for reverse-transcription quantitative polymerase chain reaction (RT-qPCR) were designed and synthesized by BioTNT Corp. (Shanghai, China).

Perfusion study. A total of 90 fresh enucleated porcine eyes from 4 to 5-month-old pigs were obtained from Jiading Town Abattoir (Shanghai, China) within $4 \mathrm{~h}$ after death for perfusion and TM-cell isolation. Atorvastatin stock solution was diluted with Dulbecco's PBS containing $5.5 \mathrm{mM}$ glucose (GPBS). The eyes were randomly divided into five treatment groups ( $\mathrm{n}=6$ each): Atorvastatin (17, 50, 100 and $200 \mu \mathrm{M}$ ) containing dimethyl sulfoxide (DMSO) $(0.38 \%)$, plus GPBS containing the same concentration of DMSO as the control group. Animal procedures were in compliance with the Statement for the Use of Animals in Ophthalmic and Vision Research by the US Association for Research in Vision and Ophthalmology. The protocol was approved by the Institutional Animal Use and Care Committee in Fudan University.

Perfusion of enucleated porcine eyes was performed as previously reported (35). Fresh porcine eyes were cleaned off extraocular tissue and the posterior segment was submerged to the limbus in PBS at $34^{\circ} \mathrm{C}$. A 21-gauge infusion needle was inserted through the peripheral cornea into the anterior chamber. This needle was carefully threaded through the pupil and the needle tip was positioned within the posterior chamber to prevent deepening of the anterior chamber that would have otherwise led to an artificial increase in outflow facility. The infusion needle was connected to polyethylene tubing, which was connected via a 3-way valve to i) a drug (or control) solution reservoir elevated relative to the eye to generate a $15-\mathrm{mmHg}$ hydrostatic pressure, and ii) a syringe containing perfusion solution (drug or GPBS) on a perfusion pump, and simultaneously a pressure sensor in parallel. The IOP in the system as monitored by the pressure sensor was recorded using a computer. The perfusion rate was regulated by adjusting the perfusion pump to maintain a constant pressure of $15 \mathrm{mmHg}$. The computer also recorded the perfusion rate ( $\mathrm{F}$ in $\mu \mathrm{l} / \mathrm{min}$ ). In addition, a second needle was inserted intracamerally into the anterior chamber and connected to a fluid collection chamber. During baseline perfusion, connections to the (drug or control solution) perfusion pump and the second (collection) needle were closed. All eyes were perfused for $30 \mathrm{~min}$ at a constant pressure of $15 \mathrm{mmHg}$ and the initial baseline aqueous outflow facility $\left(\mathrm{C}_{1}\right)$ was recorded. The $\mathrm{C}$ value was obtained by dividing the perfusion flow rate by the corresponding intraocular pressure $\left(\mathrm{C}_{1}=\mathrm{F} / \mathrm{IOP}\right.$ at baseline $)$ as described previously (3). F and IOP were constantly measured at $10 \mathrm{~Hz}$. C was calculated by averaging the values over a 10 -sec window and electronically recorded every $10 \mathrm{sec}$ by LabView version 7.1 (National Instruments, Austin, TX, USA). After 30 min, the anterior chamber content was replaced with $5 \mathrm{ml}$ atorvastatin or control solution. Solution exchange was performed by stopping the perfusion pump and opening the connections to the drug (or control) solution reservoir and the second (collection) needle to allow the solution in the drug reservoir to flow into the eye by gravity. After exchange of $5 \mathrm{ml}$ solution, connections to the reservoir containing the drug and the second (collection) needle were closed again and the perfusion pump restarted. A stable outflow facility was then obtained and recorded as $\mathrm{C}_{2}$. Total time of the perfusion was controlled within $2 \mathrm{~h}$. The difference value $\left(\mathrm{C}_{2}-\mathrm{C}_{1}\right)$ was reported as $\Delta \mathrm{C}$. The percentage change from the baseline was recorded as $\left(\Delta C / C_{1}\right)$.

Cell culture. Primary porcine TM cells were pooled from fresh porcine eyes $(n=20)$ via the tissue adherence method (36). TM cells were identified by immunofluorescence analysis of the presence of fibronectin, laminin and vimentin. TM cells were cultured in high-glucose DMEM supplemented with $10 \%$ FBS, 10,000 U/ml streptomycin and 10,000 $\mathrm{U} / \mathrm{ml}$ penicillin. Cells were maintained at $37^{\circ} \mathrm{C}$ in a humidified atmosphere containing $5 \% \mathrm{CO}_{2}$ and cells of the passages 3-5 were used in the present study.

Atorvastatin treatment and cytoskeletal staining. Fresh solutions of 10, 25, 50, 100 and $200 \mu \mathrm{M}$ atorvastatin were prepared in culture medium, whereas the control group was treated with vehicle only. The final concentration of DMSO was kept below $0.5 \%$ in the culture medium.

TM cells were cultured to confluence on $2 \%$ gelatin-coated glass coverslips and treated with atorvastatin $(10-200 \mu \mathrm{M})$ or vehicle for $24 \mathrm{~h}$. Cellular morphological changes were recorded with a phase-contrast microscope (ECLIPSE Ni-U; Nikon, Tokyo, Japan). Following drug treatment for $24 \mathrm{~h}$, the cells were fixed with $4 \%$ paraformaldehyde and permeabilized with $0.3 \%$ Triton X-100 in PBS, and subsequently blocked in $10 \%$ bovine serum albumin (Sigma-Aldrich; Merck KGaA) for $1 \mathrm{~h}$. The cells were labelled with FITC-phalloidin (1:200 
dilution) and primary antibody against vinculin or $\beta$-catenin (both 1:100 dilution) for $2 \mathrm{~h}$ at room temperature. After incubation with tetramethylrhodamine-labeled secondary antibody (Jackson ImmunoResearch Labs; West Grove, PA, USA; catalogue number: 111-025-003, 1:100 dilution) for $1 \mathrm{~h}$ at room temperature, coverslips were stained with DAPI for $1 \mathrm{~min}$ and observed with a fluorescence microscope (Nikon).

Cell viability. CCK-8 was used to evaluate the effect of atorvastatin on the viability of TM cells. At 6, 12, 24 and $48 \mathrm{~h}$ after treatment with atorvastatin $(50-200 \mu \mathrm{M})$ or vehicle, $10 \mu \mathrm{l}$ CCK-8 solution was added to $100 \mu \mathrm{l}$ TM cells per well $\left(\sim 3 \times 10^{3}\right.$ cells $)$ in 96 -well plates, cells were maintained at $37^{\circ} \mathrm{C}$ in a humidified atmosphere containing $5 \% \mathrm{CO}_{2}$ for $2 \mathrm{~h}$. Optical density (OD) at $450 \mathrm{~nm}$ was then measured using a microplate reader (BioTek, Winooski, VT, USA). The OD value was used for quantification of cell proliferation at the different dosages of atorvastatin as well as different time-points, following the manufacturer's protocol.

$R T-q P C R$. To determine the effect of atorvastatin on the expression of vinculin and $\beta$-catenin, total RNA from atorvastatin $(50-200 \mu \mathrm{M})$ or vehicle-treated $0-48 \mathrm{~h}$ TM cells was isolated using TRIzol reagent (Invitrogen; Thermo Fisher Scientific, Inc.) and reverse-transcribed to complementary (c)DNA using a First-Strand cDNA synthesis kit (BioTNT, Shanghai, China; catalogue number: A2010B0B01) according to the manufacturer's protocol. The cDNA was then amplified by PCR using sequence-specific forward and reverse oligonucleotide primers: Vinculin, forward 5'-ACCAGG CTCCCAAGACCCAT-3' and reverse 5'-CAGGCGAGTCAG CAGCAACA-3'; $\beta$-catenin, forward 5'-GAGGACAAGCCC CAGGATTA-3' and reverse 5'-AGCAGTCTCATTCCAAGC CA-3'; and GAPDH, forward 5'-CGGAGTCAACGGATT TGGTCGTAT-3' and reverse 5'-AGCCTTCTCCATGGT GGTGAAGAC-3'. A real time qPCR kit (BioTNT, Shanghai, China; catalogue number: A2010A001) was used according to the manufacturer's protocol to create the $\mathrm{PCR}$ reaction mixtures composed of buffers, dNTP, heat activated Taq DNA polymerase mixtures, $\mathrm{MgCl}_{2}$ solution and premixed SYBR GREEN dyes. Amplification was performed at $95^{\circ} \mathrm{C}, 5 \mathrm{~min}$; $95^{\circ} \mathrm{C}, 5 \mathrm{sec}, 60^{\circ} \mathrm{C}, 30 \mathrm{sec}$ for 40 cycles. mRNA expression was analyzed on the ABI 7500 qRT-PCR System (Applied Biosystems; Thermo Fisher Scientific, Inc.) (37).

Western blot analysis. Lysates of TM cells treated with atorvastatin $(50-200 \mu \mathrm{M})$ or vehicle for $0-48 \mathrm{~h}$ were prepared using radioimmunoprecipitation assay buffer (Beyotime Institute of Biotechnology, Shanghai, China) containing phenylmethylsulfonyl fluoride, a protease inhibitor. Protein concentration was determined using the BCA assay (Yeasen, Shanghai, China; catalogue number: 20201ES76) according to the manufacturer's protocol using bovine serum albumin as a standard. Protein extracts (20 $\mu \mathrm{g}$ protein/lane) were separated by SDS-PAGE (10\% acrylamide) and transferred onto a polyvinylidene fluoride membrane (EMD Millipore; Billerica, MA, USA). The membrane was then probed overnight using antibodies specifically directed against vinculin (Boster Biological Technology, Ltd., Wuhan, China; BM4051, 1:100 dilution), $\beta$-catenin (Boster Biological
Technology, Ltd., BM3905, 1:100 dilution) and GAPDH (Cell Signaling Technology, Inc., Danvers, MA, USA; catalogue number: 2118 ; 1:1,000 dilution) at $4^{\circ} \mathrm{C}$, followed by incubation with horseradish peroxidase-conjugated goat anti-rabbit secondary antibody (Solarbio, Beijing, China; catalogue number: SE134; 1:1,000 dilution) at room temperature for $1 \mathrm{~h}$. Specific bands were visualized by Odyssey infrared imaging system (LI-COR, Inc., Lincoln, NE, USA). The signals were analyzed using ImageJ software (version 1.48v; National Institutes of Health, Bethesda, MD, USA). The band densities of each sample were normalized to the respective GAPDH band. All results were repeated three times.

Reversibility of drug-induced effects. To evaluate whether the atorvastatin-induced effect is reversible, the medium of TM cells treated with atorvastatin $(100 \mu \mathrm{M})$ for $48 \mathrm{~h}$ was replaced with culture medium after washing with PBS. The reversibility of cellular morphological changes was observed using a phase-contrast microscope and images were captured. At $24 \mathrm{~h}$ after drug washout, cells were fixed and stained for F-actin, vinculin and $\beta$-catenin using the same procedures described in Atorvastatin treatment and cytoskeletal staining section.

Statistical analysis. Data were analyzed using STATA version 12.0 software (StataCorp LLC, College Station, TX, USA). Values are expressed as the mean \pm standard error. One-way analysis of variance followed by Bonferroni's multiple comparisons test was used for statistical comparisons of multiple groups. $\mathrm{P}<0.05$ was considered to indicate a statistically significant difference.

\section{Results}

Effects of atorvastatin on aqueous outflow facility in enucleated porcine eyes. As expected, there was no significant difference baseline outflow facility $\left(\mathrm{C}_{1}\right)$ values among all treatment groups (Fig. 1A). There was no significant difference in outflow facility between the control and $17 \mu \mathrm{M}$ atorvastatin-treated group. Concentrations of atorvastatin of $\geq 50 \mu \mathrm{M}$ significantly increased the outflow facility. $\mathrm{C}_{2}$ value in the 50 , 100 and $200 \mu \mathrm{M}$ groups was significantly increased compared with $\mathrm{C}_{1}$ value in each group (6.96-, 9.59- and 6.99-fold increase, respectively; Fig. 1A). There was no significant difference among the three higher-concentration groups (Fig. 1B).

Effects of atorvastatin on cell morphology. Treatment of confluent TM cells with atorvastatin $(10-200 \mu \mathrm{M})$ for $24 \mathrm{~h}$ led to certain morphological changes. Compared with the control group, no obvious morphological changes were detected in TM cells treated with $10 \mu \mathrm{M}$ atorvastatin. However, cells treated with ${ }^{3} 25 \mu \mathrm{M}$ atorvastatin exhibited progressive cell rounding and separation among cells, while the cells did not detach from the culture dish (Fig. 2). Similar results were observed in three independent experiments.

Cell viability. To evaluate the potential effect of atorvastatin on cell viability, porcine TM cells were treated with 50-200 $\mu \mathrm{M}$ atorvastatin and subjected to a CCK-8 assay at 6, 12, 24 and $48 \mathrm{~h}$. Compared with that in the mock-treated group, no significant change in cell viability was detected after treatment with 
A

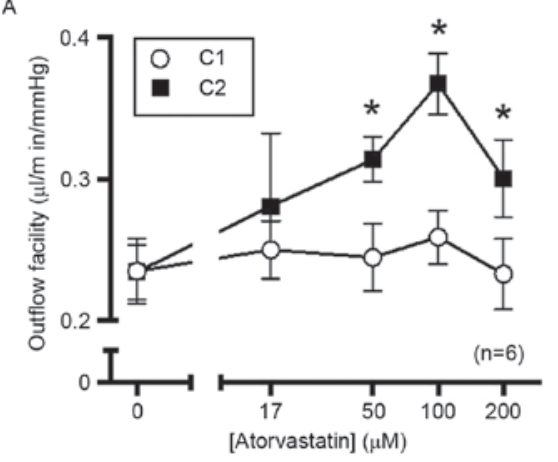

B

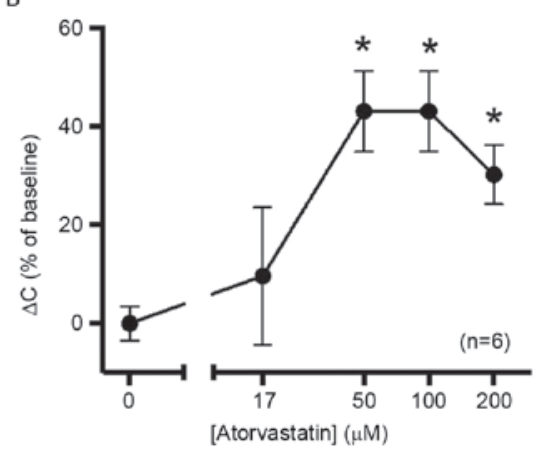

Figure 1. Atorvastatin increases outflow in enucleated porcine eyes. After establishing the initial baseline outflow facility, eyes were perfused with $17,50,100$ or $200 \mu \mathrm{M}$ atorvastatin dissolved in GPBS containing DMSO (0.38\%). Contralateral control eyes were perfused with GPBS containing DMSO alone, with outflow facility measured at $10 \mathrm{~Hz}$. Time of perfusion was controlled within $2 \mathrm{~h}$ to avoid the 'washout' effect. (A) Baseline outflow facility values were not significantly different among all groups. Compared with the control group, 50, 100 and $200 \mu \mathrm{M}$ atorvastatin significantly increased the outflow facility, while $17 \mu \mathrm{M}$ atorvastatin did not have any significant effect. (B) The percentage change from baseline exhibited and a typical dose-response association. ${ }^{*} \mathrm{P}<0.05$ vs. $0 \mu \mathrm{M}$ atorvastatin. $\mathrm{C}_{1}$, outflow facility at baseline; $\mathrm{C}_{2}$, outflow facility after treatment; DMSO, dimethyl sulfoxide; GPBS, PBS containing 5.5 mM glucose; $\Delta \mathrm{C}$, change of outflow.
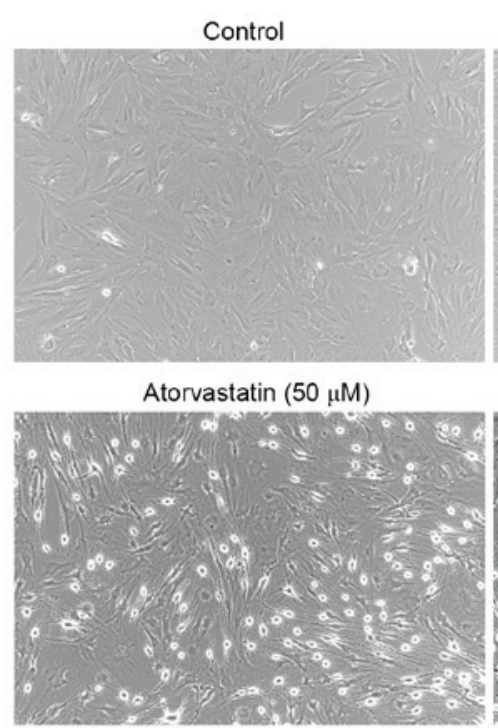

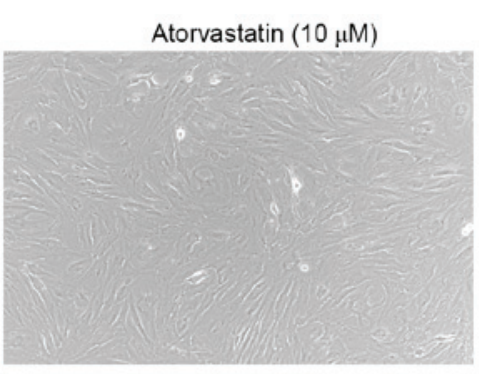

Atorvastatin $(100 \mu \mathrm{M})$

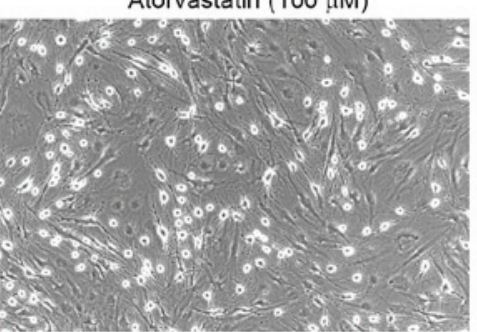

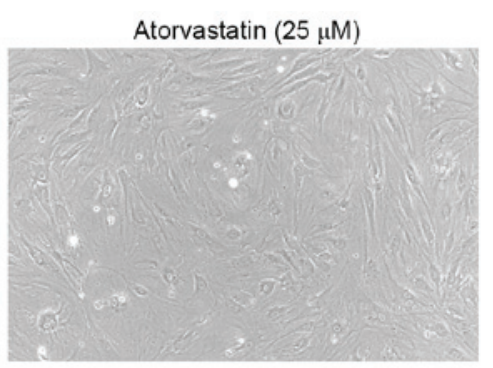

Atorvastatin $(200 \mu \mathrm{M})$

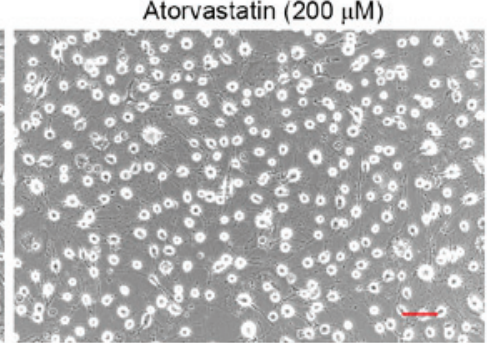

Figure 2. Atorvastatin (10-200 $\mu \mathrm{M})$ induces morphological changes in TM cells. Treatment with $10-200 \mu \mathrm{M}$ atorvastatin for $24 \mathrm{~h}$ caused dose-dependent changes in the shape of TM cells in confluent culture, including cell rounding and cell-cell separation, compared with control cells. Similar results were observed in three independent experiments (scale bar, $100 \mu \mathrm{m}$ ). TM, trabecular meshwork.

atorvastatin $(50-100 \mu \mathrm{M})$ for $48 \mathrm{~h}$. However, the cell viability indicated a downtrend in the group treated with $200 \mu \mathrm{M}$ atorvastatin after $24 \mathrm{~h}$; although this was not significantly different. (Fig. 3). Therefore, these findings suggest that high concentrations of atorvastatin may inhibit TM cell viability. And experimental results may be statistically significant after extending the intervention time.

Effects of atorvastatin on cytoskeletal organization and focal adhesion of TM cells. From Fig. 4, it may be observed that the distribution of F-actin (green) in the mock-TM cells was relatively uniform, while vinculin (red) and $\beta$-catenin (red) were mainly distributed around the nuclei. A dose-dependent, marked reduction of F-actin and changes in the distribution of vinculin and $\beta$-catenin were observed in TM cells following $24 \mathrm{~h}$ of treatment with atorvastatin $(10-200 \mu \mathrm{M})$. An association between changes in the actin cytoskeletal organization/distribution of focal adhesions and morphological changes in TM cells was apparent (Fig. 4).

Effects of atorvastatin on expression of vinculin and $\beta$-catenin . To confirm the results obtained by immunohistochemistry, RT-qPCR and western blot analysis were performed. Compared with that in control cells, the expression of vinculin and $\beta$-catenin mRNA was significantly decreased in TM cells treated with $100 \mu \mathrm{M}$ atorvastatin for durations of $\geq 12 \mathrm{~h}$ (Fig. 5A and B). Similar results were obtained by western blot analysis, which demonstrated that the expression of vinculin and $\beta$-catenin protein was decreased by atorvastatin (Fig. 5C and D).

Reversal of atorvastatin-induced morphological and cytoskeletal changes. Of note, the atorvastatin-induced morphological changes, modification of F-actin organization 


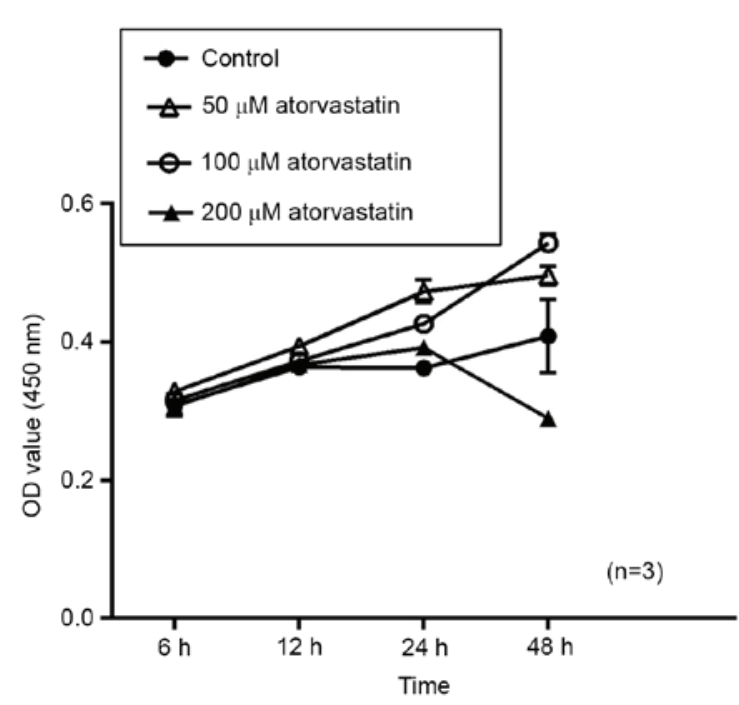

Figure 3. Effect of atorvastatin on the viability of trabecular meshwork cells. OD values for the cell viability assay were measured at $6,12,24$ and $48 \mathrm{~h}$ after drug treatment. Treatment with 50 or $100 \mu \mathrm{M}$ atorvastatin, did not significantly affect the cell viability. In the group treated with $200 \mu \mathrm{M}$ atorvastatin, the cell viability revealed a downtrend after $24 \mathrm{~h}$ with no statistical significance. In certain instances, the standard error of the mean bar was smaller than the size of the symbol. OD, optical density.

and focal adhesions were reverted to those prior to treatment within $24 \mathrm{~h}$ of replacing the culture supernatant with atorvastatin-free medium (Fig. 6).

\section{Discussion}

The present study aimed to determine the effects of atorvastatin on TM cells and the aqueous humour outflow pathway of enucleated porcine eyes. The results demonstrated that atorvastatin increased the aqueous humour outflow facility in the whole-eye perfusion model, which was also identified to be associated with changes in TM cell morphology as well as the distribution of actin cytoskeleton and focal adhesions in vitro.

The present study indicated that no detectable washout effect was observed within $2 \mathrm{~h}$. Compared with that in the control group, atorvastatin increased the aqueous humour outflow facility in enucleated porcine eyes in a dose-dependent manner. The magnitude of this increase was comparable to the previously reported $40 \%$ facility increase observed in an organ-cultured porcine eye anterior segment perfused with $100 \mu \mathrm{M}$ lovastatin for $45 \mathrm{~h}$ (23), and was less than the $80 \%$ facility increase observed in porcine eyes after perfusion with Y-27632 for $3 \mathrm{~h}$ (15). Furthermore, atorvastatin takes effect more rapidly than lovastatin in increasing aqueous humour outflow. In the present study, the perfusion time was limited to $2 \mathrm{~h}$ to minimize the washout effect, and to explore the short-term effectiveness of atorvastatin in improving outflow facility. 'Washout' is a phenomenon occurring in eyes of non-human species referring to a time-dependent increase in outflow facility $(38,39)$, while it has remained controversial whether the washout effect is present in porcine eyes $(40,41)$. A typical washout effect is $6-26 \%$ for different durations of perfusion (15,41-43).

Subsequently, the in vivo observation of the present study was confirmed in vitro, as atorvastatin treatment caused significant changes in cellular morphology and the localization

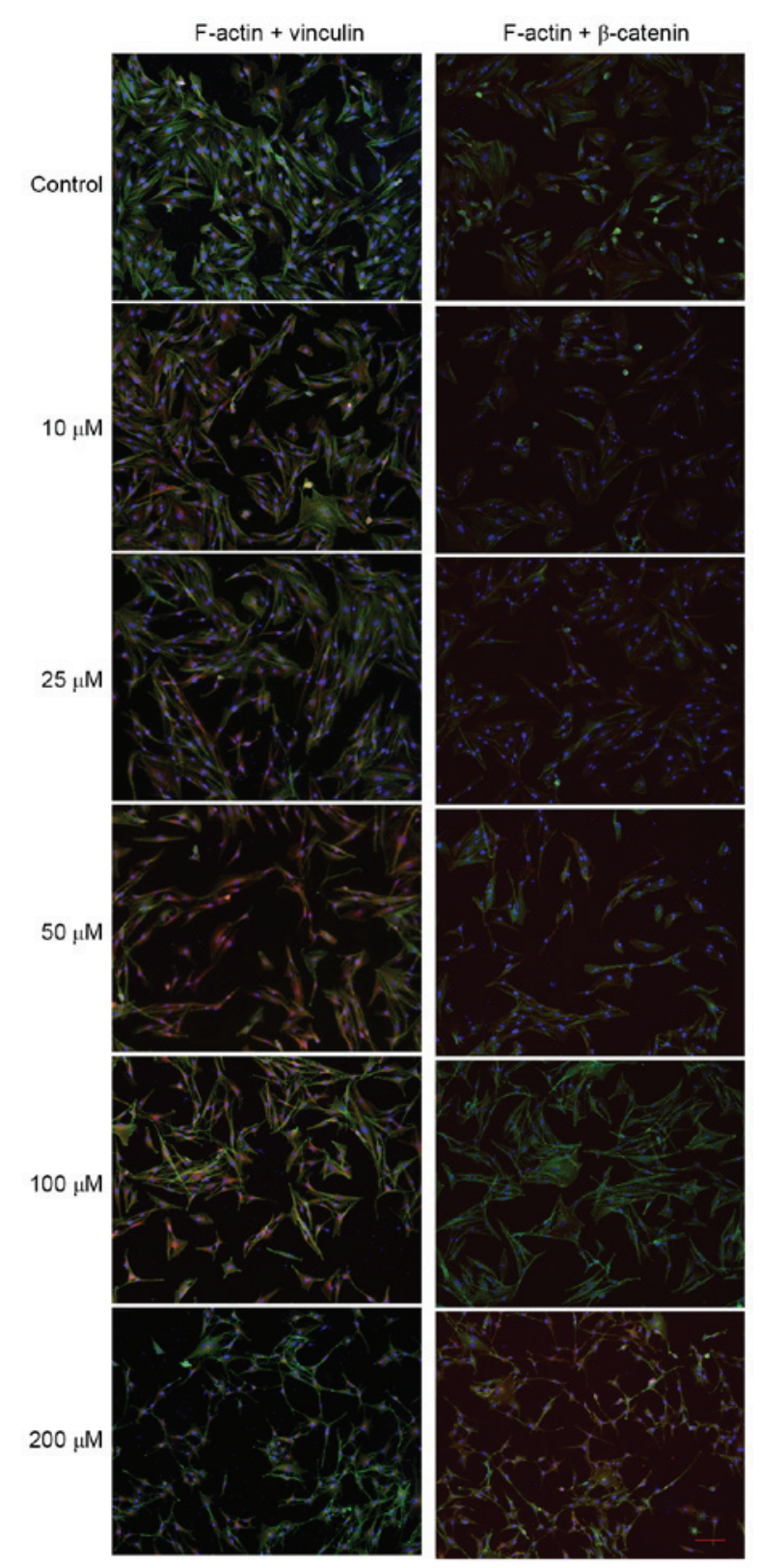

Figure 4. Atorvastatin-induced changes in cell shape, F-actin, focal adhesions and adherens junctions in TM cells. After treatment with atorvastatin (10-200 $\mu \mathrm{M}$ ) for $24 \mathrm{~h}$, TM cells were fixed and stained for nuclei (blue), F-actin (green) and vinculin (red) or $\beta$-catenin (red). In TM cells, the change of actin cytoskeletal organization and distribution of focal adhesions induced by atorvastatin was in accordance with cell shape changes (scale bar, $100 \mu \mathrm{m})$. TM, trabecular meshwork.

of cell-cell focal adhesions. The actin cytoskeleton and focal adhesions are important structures for numerous cell functions. Upon a decrease of cell-cell adhesions and cell-ECM junctions, the intercellular space, through which the aqueous humour flows, is expanded (10), which may increase the outflow facility and decrease IOP. In the present study, we speculate that atorvastatin treatment decreased the expression of vinculin and $\beta$-catenin at the mRNA and the protein level, and relaxed the actin cytoskeleton via inhibiting the synthesis of Rho GTPase. The change of cell morphology and adhesions regulates the hydrodynamics of aqueous humour outflow. The present study demonstrated that atorvastatin may affect the aqueous humour outflow pathway at the cellular level. 
A

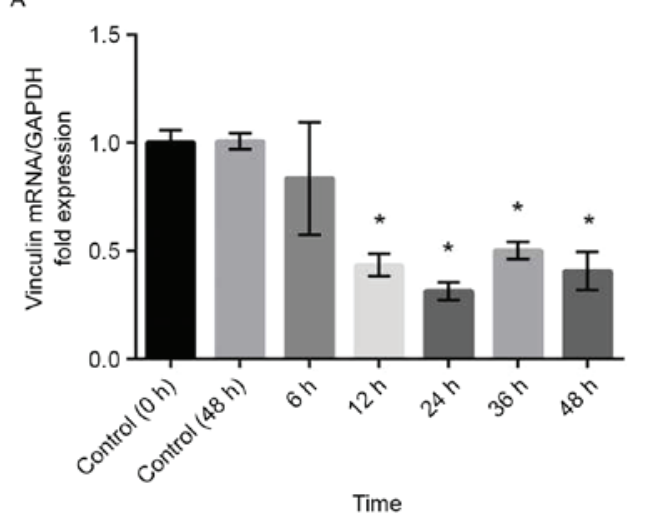

C

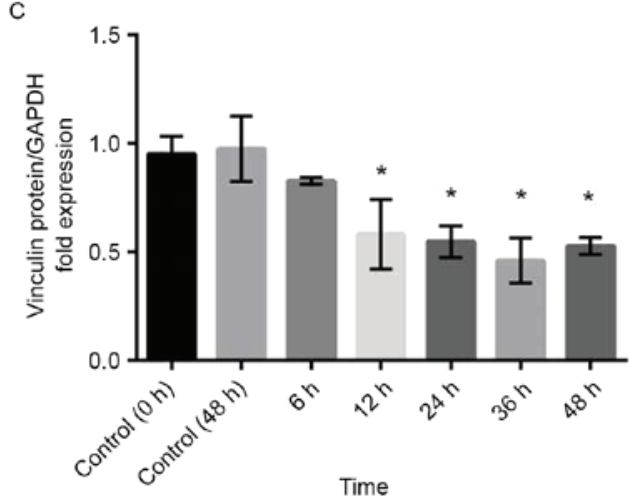

B

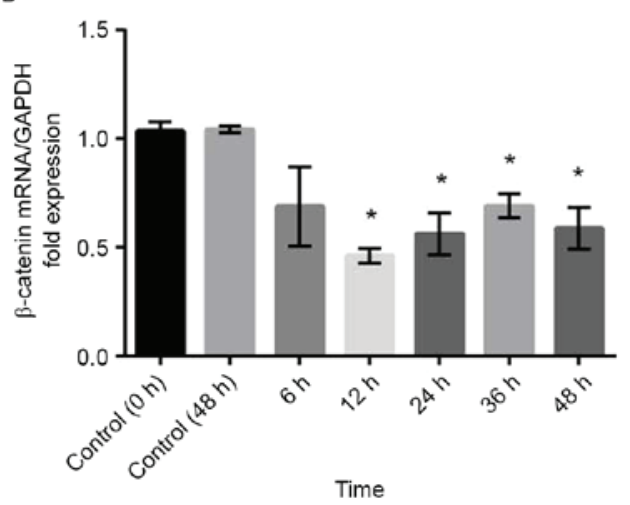

D

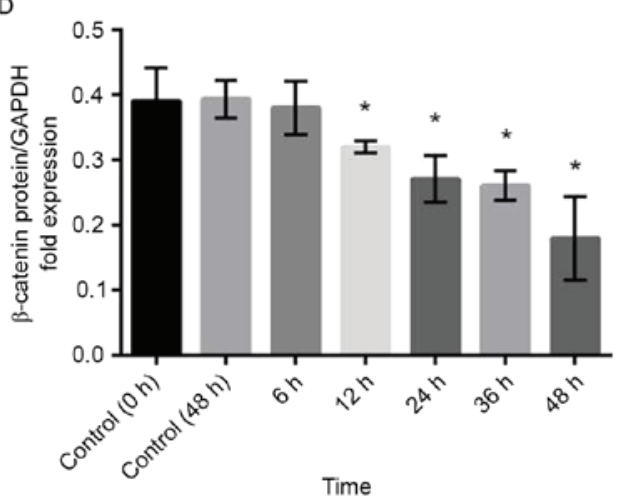

Figure 5. Atorvastatin $(100 \mu \mathrm{M})$ decreased mRNA and protein levels of vinculin and $\beta$-catenin in porcine trabecular meshwork cells. After treatment with atorvastatin for $12 \mathrm{~h}$, the mRNA levels of (A) vinculin and (B) $\beta$-catenin as well as the protein levels of (C) vinculin and (D) $\beta$-catenin demonstrated a significant decrease. Values are expressed as the mean and standard error of the mean from three independent experiments. ${ }^{*}<0.05$ vs. Control.

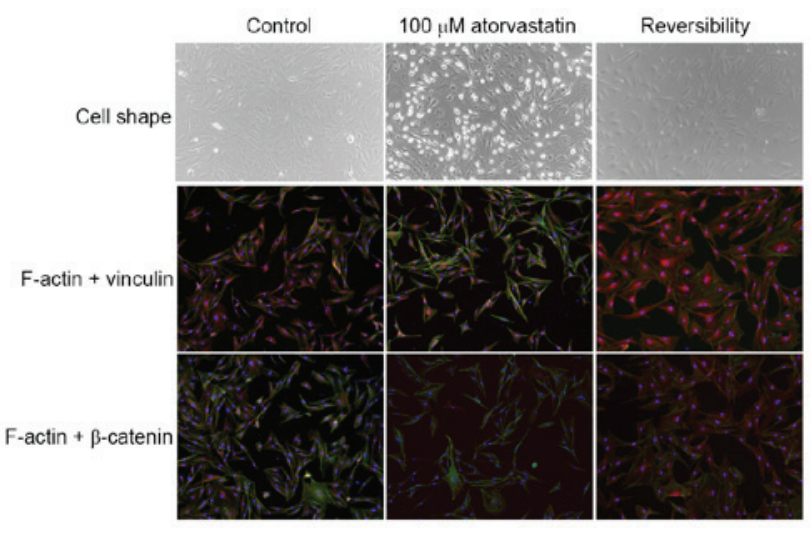

Figure 6. Reversibility of atorvastatin-induced changes in TM cell morphology and actin cytoskeletal organization. Left column: Untreated control TM cells. Middle column: TM cells treated with $100 \mu \mathrm{M}$ atorvastatin for $48 \mathrm{~h}$. Right column: TM cells treated with $100 \mu \mathrm{M}$ atorvastatin for $48 \mathrm{~h}$ and then without the drug for an additional $24 \mathrm{~h}$, demonstrating reversal of drug-induced changes. Cells were fixed and stained for F-actin (green) and focal adhesions vinculin (red) or $\beta$-catenin (red). These results were confirmed in three independent experiments (scale bar, $100 \mu \mathrm{m}$ ). TM, trabecular meshwork.

The effects of statins on cell morphology typically require at least $18 \mathrm{~h}$ (23). In the present study, atorvastatin at concentrations of $>17 \mu \mathrm{M}$ significantly elevated the outflow facility within $2 \mathrm{~h}$ in the whole-eye perfusion system. In addition, atorvastatin at concentrations of $>10 \mu \mathrm{M}$ affected TM cell morphology within $24 \mathrm{~h}$, suggesting that the statin concentration is an important factor in the modification of cell morphology and aqueous humour outflow.

It is acknowledged that the present study had certain limitations; for instance, changes in outflow in the single-pressure perfusion system do not differentiate between pressure-dependent (largely trabecular) or pressure-independent (uveoscleral) outflow. A multiple-pressure study will be performed in the future.

In conclusion, atorvastatin, a cholesterol-lowering drug, elevated aqueous humour outflow facility in a porcine whole-eye perfusion model within $2 \mathrm{~h}$. The effect was associated with TM cell relaxation and decreased expression of focal adhesion proteins in TM cells. It was therefore demonstrated that atorvastatin decreased the IOP in vivo and in vitro. It was speculated that the effects of atorvastatin may be via blocking the Rho/ROCK signalling pathway. The present results enhanced the current knowledge on the effect of statins themselves on the morphology of TM cells and the contractile tone of the aqueous outflow pathway (44). The results may provide evidence that atorvastatin is a novel therapeutic agent for POAG. The present study exemplified that novel treatment methods for POAG may be identified by exploring clinically known drugs. Further animal experiments and clinical studies may be required to confirm the potential value of atorvastatin in the treatment of POAG.

\section{Acknowledgements}

The present study was sponsored by the Natural Science Foundation of Shanghai (Grant no. 16ZR1404500). 


\section{References}

1. Overby DR, Stamer WD and Johnson M: The changing paradigm of outflow resistance generation: Towards synergistic models of the JCT and inner wall endothelium. Exp Eye Res 88: 656-670, 2009.

2. Fuchshofer R and Tamm ER: Modulation of extracellular matrix turnover in the trabecular meshwork. Exp Eye Res 88: 683-688, 2009.

3. Grant WM: Experimental aqueous perfusion in enucleated human eyes. Arch Ophthalmol 69: 783-801, 1963.

4. Picht G, Welge-Luessen U, Grehn F and Lütjen-Drecoll E: Transforming growth factor beta 2 levels in the aqueous humor in different types of glaucoma and the relation to filtering bleb development. Graefes Arch Clin Exp Ophthalmol 239: 199-207, 2001.

5. Johnson M: 'What controls aqueous humour outflow resistance?' Exp Eye Res 82: 545-557, 2006.

6. Tamm ER and Fuchshofer R: What increases outflow resistance in primary open-angle glaucoma? Surv Ophthalmol 52 (Suppl 2): S101-S104, 2007.

7. Ethier CR, Read AT and Chan DW: Effects of latrunculin-B on outflow facility and trabecular meshwork structure in human eyes. Invest Ophthalmol Vis Sci 47: 1991-1998, 2006.

8. Bahler CK, Hann CR, Fautsch MP and Johnson DH Pharmacologic disruption of Schlemm's canal cells and outflow facility in anterior segments of human eyes. Invest Ophthalmo Vis Sci 45: 2246-2254, 2004.

9. Hu Y, Gabelt BT and Kaufman PL: Monkey organ-cultured anterior segments: Technique and response to H-7. Exp Eye Res 82: 1100-1108, 2006

10. Tian B, Gabelt BT, Geiger B and Kaufman PL: The role of the actomyosin system in regulating trabecular fluid outflow. Exp Eye Res 88: 713-717, 2009.

11. Bornstein P: Matricellular proteins: An overview. J Cell Commun Signal 3: 163-165, 2009.

12. Haddadin RI, Oh DJ, Kang MH, Filippopoulos T, Gupta M, Hart L Sage EH and Rhee DJ: SPARC-null mice exhibit lower intraocular pressures. Invest Ophthalmol Vis Sci 50: 3771-3777, 2009.

13. Clark AF and Pang IH: Advances in glaucoma therapeutics. Expert Opin Emerg Drugs 7: 141-163, 2002.

14. Cai S, Liu X, Glasser A, Volberg T, Filla M, Geiger B, Polansky JR and Kaufman PL: Effect of latrunculin-A on morphology and actin-associated adhesions of cultured human trabecular meshwork cells. Mol Vis 6: 132-143, 2000.

15. Rao PV, Deng PF, Kumar J and Epstein DL: Modulation of aqueous humor outflow facility by the Rho kinase-specific inhibitor Y-27632. Invest Ophthalmol Vis Sci 42: 1029-1037, 2001.

16. Gabelt BT, Hu Y, Vittitow JL, Rasmussen CR, Grosheva I, Bershadsky AD, Geiger B, Borrás T and Kaufman PL: Caldesmon transgene expression disrupts focal adhesions in HTM cells and increases outflow facility in organ-cultured human and monkey anterior segments. Exp Eye Res 82: 935-944, 2006.

17. Downs JR, Clearfield M, Weis S, Whitney E, Shapiro DR, Beere PA, Langendorfer A, Stein EA, Kruyer W and Gotto AM Jr: Primary prevention of acute coronary events with lovastatin in men and women with average cholesterol levels: Results of AFCAPS/TexCAPS. Air force/texas coronary atherosclerosis prevention study. JAMA 279: 1615-1622, 1998

18. Endo A: The discovery and development of HMG-CoA reductase inhibitors. J Lipid Res 33: 1569-1582, 1992.

19. Vaughan CJ and Delanty N: Neuroprotective properties of statins in cerebral ischemia and stroke. Stroke 30: 1969-1973, 1999.

20. Zacco A, Togo J, Spence K, Ellis A, Lloyd D, Furlong S and Piser T: 3-hydroxy-3-methylglutaryl coenzyme A reductase inhibitors protect cortical neurons from excitotoxicity. J Neurosci 23: 11104-11111, 2003.

21. Schmeer C, Kretz A and Isenmann S: Statin-mediated protective effects in the central nervous system: General mechanisms and putative role of stress proteins. Restor Neurol Neurosci 24: 79-95, 2006.

22. Yin H, Gui Y and Zheng XL: 2-methoxyestradiol inhibits atorvastatin-induced rounding of human vascular smooth muscle cells J Cell Physiol 222: 556-564, 2010.

23. Song J, Deng PF, Stinnett SS, Epstein DL and Rao PV: Effects of cholesterol-lowering statins on the aqueous humor outflow pathway. Invest Ophthalmol Vis Sci 46: 2424-2432, 2005.

24. Burridge $K$ and Wennerberg $K$ : Rho and Rac take center stage. Cell 116: 167-179, 2004.
25. Etienne-Manneville S and Hall A: Rho GTPases in cell biology. Nature 420: 629-635, 2002.

26. Kaibuchi K, Kuroda S and Amano M: Regulation of the cytoskeleton and cell adhesion by the Rho family GTPases in mammalian cells. Annu Rev Biochem 68: 459-486, 1999.

27. Somlyo AP and Somlyo AV: Signal transduction through the RhoA/Rho-kinase pathway in smooth muscle. J Muscle Res Cell Motil 25: 613-615, 2004.

28. Wang J, Liu X and Zhong Y: Rho/Rho-associated kinase pathway in glaucoma (Review). Int J Oncol 43: 1357-1367, 2013

29. Stein JD, Newman-Casey PA, Talwar N, Nan B, Richards JE and Musch DC: The relationship between statin use and open-angle glaucoma. Ophthalmology 119: 2074-2081,2012.

30. De Castro DK, Punjabi OS, Bostrom AG, Stamper RL,Lietman TM, Ray K and Lin SC: Effect of statin drugs and aspirin on progression in open-angle glaucoma suspects using confocal scanning laser ophthalmoscopy. Clin Exp Ophthalmol 35: 506-513, 2007.

31. Openkova YY, Korobeiynikova EN, Rykin VS and Vinkova GA: The analysis of status of biochemical indicators in blood serum and lacrimal fluid in patients with primary open-angle glaucoma. Klin Lab Diagn: 8-11, 2013 (In Russian).

32. DiNicolantonio JJ, Lavie CJ, Serebruany VL and O'Keefe JH: Statin wars: The heavyweight match-atorvastatin versus rosuvastatin for the treatment of atherosclerosis, heart failure, and chronic kidney disease. Postgrad Med 125: 7-16, 2013.

33. Stoekenbroek RM, Boekholdt SM, Fayyad R, Laskey R, Tikkanen MJ,Pedersen TR and Hovingh GK; Incremental Decrease in End Points Through Aggressive Lipid Lowering Study Group: High-dose atorvastatin is superior to moderate-dose simvastatin in preventing peripheral arterial disease. Heart 101: 356-362, 2015.

34. Sillesen H, Amarenco P, Hennerici MG, Callahan A, Goldstein LB, Zivin J, Messig M and Welch KM; Stroke Prevention by Aggressive Reduction in Cholesterol Levels Investigators: Atorvastatin reduces the risk of cardiovascular events in patients with carotic atherosclerosis: A secondary analysis of the stroke prevention by aggressive reduction in cholesterol levels (SPARCL) trial. Stroke 39: 3297-3302, 2008.

35. Zhang Y, Toris CB, Liu Y, Ye W and Gong H: Morphological and hydrodynamic correlates in monkey eyes with laser induced glaucoma. Exp Eye Res 89: 748-756, 2009.

36. Polansky JR, Weinreb RN, Baxter JD and Alvarado J: Human trabecular cells. I. Establishment in tissue culture and growth characteristics. Invest Ophthalmol Vis Sci 18: 1043-1049, 1979.

37. Livak KJ and Schmittgen TD: Analysis of relative gene expression data using real-time quantitative PCR and the 2(-Delta Delta C(T)) method. Methods 25: 402-408, 2001.

38. Barany EH and Gassmann HB: The effect of death on outflow resistance in normal and sympathectomized rabbit eyes. Invest Ophthalmol 4: 206-210, 1965.

39. Erickson-Lamy K, Schroeder AM, Bassett-Chu S and Epstein DL: Absence of time-dependent facility increase ("washout") in the perfused enucleated human eye. Invest Ophthalmol Vis Sci 31: 2384-2388, 1990.

40. Vaajanen A, Vapaatalo $\mathrm{H}$ and Oksala O: A modified in vitro method for aqueous humor outflow studies in enucleated porcine eyes. J Ocul Pharmacol Ther 23: 124-131, 2007.

41. Rao PV, Deng P, Sasaki Y and Epstein DL: Regulation of myosin light chain phosphorylation in the trabecular meshwork: Role in aqueous humour outflow facility. Exp Eye Res 80: 197-206, 2005.

42. Khurana RN, Deng PF, Epstein DL and Vasantha Rao P: The role of protein kinase $\mathrm{C}$ in modulation of aqueous humor outflow facility. Exp Eye Res 76: 39-47, 2003.

43. Epstein DL, Roberts BC and Skinner LL: Nonsulfhydryl-reactive phenoxyacetic acids increase aqueous humor outflow facility. Invest Ophthalmol Vis Sci 38: 1526-1534, 1997.

44. Pokrovskaya O, Wallace D and O'Brien C: The emerging role of statins in glaucoma pathological mechanisms and therapeutics. Open J Ophthalmol 4: 124-138, 2014.

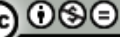

This work is licensed under a Creative Commons Attribution-NonCommercial-NoDerivatives 4.0 International (CC BY-NC-ND 4.0) License. 